\title{
Beyond the articulatory loop: A semantic contribution to serial order recall of subspan lists
}

\author{
DERRICK C. BOURASSA and DEREK BESNER \\ University of Waterloo, Waterloo, Ontario, Canada
}

\begin{abstract}
In two experiments, serial order recall of short lists of content and function words under quiet and articulatory suppression conditions was examined in order to assess the hypotheses that (1) semantic attributes of words contribute to short-term-memory performance, and (2) do so independently of effects attributable to the articulatory loop component. In Experiment 1, content words were better recalled than function words; both word types were equally impaired by suppression. This provides support for the notion that semantic coding makes an independent contribution to span performance. This word-class effect disappeared in Experiment 2, when content and function words were matched for imageability. These data suggest that at least some aspects of meaning contribute to serial order recall performance for short lists, independently of the articulatory loop.
\end{abstract}

There is little doubt that long-term memory contributes to short-term-memory performance, even beyond Miller's (1956) expectations. Case studies have provided examples of individuals with the ability to use interitem associations to produce memory spans of up to 100 numbers (e.g., Ericsson, Chase, \& Faloon, 1980; Staszewski, 1988). What is less clear is the nature of long-term memory's contribution to "span" performance (as defined in Baddeley, Thomson, \& Buchanan, 1975) in the absence of interitem associations. Some research suggests that long-term memory in the form of lexical information facilitates performance in the memory span task (e.g., Besner \& Davelaar, 1982; Hulme, Maughan, \& Brown, 1991). In the present experiments, we evaluate the proposition that semantic information also serves this purpose.

When an individual is given a series of items for serial order recall, it is commonly assumed that the articulatory loop initially serves to code the articulatory features of these items (Baddeley \& Hitch, 1974). Further, because these articulatory codes are susceptible to passive decay over time, the articulatory loop maintains the activation of these codes through a rehearsal process that is "analogous to a recirculating tape loop, in which items [are] constantly being read and rewritten to overcome the effects of decay" (Hulme \& Tordoff, 1989, p. 82).

An obvious prediction of this trace decay account is that span performance increases as a function of the efficiency of the articulatory loop. Several investigations (e.g., Baddeley et al., 1975; Hulme \& Tordoff, 1989) have dem-

This research was supported by Grant AO988 from the Natural Sciences and Engineering Research Council of Canada to D. Besner, and an NSERC Postgraduate scholarship to D. Bourassa. We are grateful to Tom Yoannidis for data collection, H. L. Roediger III for editorial assistance, and, particularly, to Sue Gathercole for her review. Address correspondence to either author at Psychology Department, University of Waterloo, Waterloo, Ontario, Canada N2L 3G1 (e-mail: DBourass@ Watarts.UWaterloo.Ca or DBesner@Watarts.UWaterloo.Ca). onstrated that this is indeed the case. A stronger assumption of the trace decay account is that the efficiency of the articulatory loop is the only determinant of span performance. However, several investigations (e.g., Besner \& Davelaar, 1982; Hulme et al., 1991) have provided evidence suggesting that long-term memory influences span performance in a manner that is independent of the functioning of the articulatory loop. These investigations have employed manipulations designed to differentially affect the functioning of both the articulatory loop and long-term memory. The observation that these manipulations produce statistically independent effects on performance supports the notion that the contributions of the articulatory loop and long-term memory to memory span are distinct.

It is well known that articulatory suppression (whereby subjects repeatedly utter some irrelevant material such as " $1,2,3,4 \ldots$, ) strongly disrupts serial order recall of subspan lists (e.g., Baddeley et al., 1975; Besner \& Davelaar, 1982; Murray, 1968). It is widely assumed that suppression interferes with the maintenance of information in the articulatory loop (Baddeley, 1986). An example that serves to illustrate this point is from Baddeley et al. (1975; see also Caplan, Rochon, \& Waters, 1992), who reported that, under quiet conditions, more items can be recalled in the span task if they are of short rather than long duration. Suppression eliminates this word-length effect. The standard interpretation of this result is that the word-length effect reflects the process of articulatory rehearsal: Because the articulatory loop is time limited, it can accommodate a greater number of items if they are of short rather than long duration. Eliminating the process of rehearsal with articulatory suppression removes this effect.

Besner and Davelaar (1982, Experiment 2) examined serial order recall for lists presented under quiet and suppression conditions. The items in the list varied in syllable length and lexical status. Under quiet conditions, the 
lists of items with fewer syllables were better recalled than were the lists of items with more syllables, and the lists with entries in a phonological lexicon (e.g., BRANE) were better recalled than were the lists in which the items did not enjoy lexical status (e.g., sLINT). Under suppression conditions, the word-length effect was eliminated but the lexicality effect persisted. Besner and Davelaar argued that this dissociation shows that suppression has distinct effects in the span task: It inhibits the maintenance of serial order information (hence the elimination of the wordlength effect), but does not prevent a phonological code from accessing lexical memory (hence the advantage of BRANE Over SLINT).

In the context of the trace decay account outlined above, the additive effects of lexicality and suppression imply the existence of a component of short-term-memory performance that is independent of any contributions from the articulatory loop. If rehearsal in the articulatory loop were sensitive to the lexical status of items being rehearsed, then suppression should have eliminated or at least reduced the lexicality effect in the same manner that it eliminates the word-length effect.

Hulme et al. (1991) provide converging evidence for the proposition that lexicality affects short-term-memory performance independently of the articulatory loop. They examined span performance for lists of words or nonwords when syllable length was also manipulated. Consistent with past research, span performance for items with fewer syllables was superior. More critically, words were better recalled than nonwords, and this lexicality effect did not interact with syllable length.

Hulme et al. (1991) concluded that the additive effects of these factors in their experiment support a two-process account of span performance. The equivalent syllable length effect for both words and nonwords "suggests that the [articulatory] loop must maintain information in a nonlexical code" (p. 691). However, "the difference in recall between words and nonwords is consistent with the view that words benefit from storage in some long-term memory system in addition to [italics added] being held in the articulatory loop" (p. 691).

The investigations of Besner and Davelaar (1982) and Hulme et al. (1991) clearly demonstrate that long-term memory influences memory span independently of effects attributable to the articulatory loop. Less clear, however, is precisely which aspects of long-term memory contribute to span performance. These researchers describe their effects as lexical contributions, but lexical factors are typically confounded with semantic factors. ${ }^{1}$ That is, are the effects simply due to the fact that words and pseudohomophones activate lexical representations within the wordrecognition system, or are they due to the fact that these items also activate meaning representations? ${ }^{2}$ A distinction between lexical and semantic information has long existed in the word-recognition literature (e.g., Morton, 1969), and is applicable here. Indeed, Hulme et al. acknowledge this fact: "It is quite possible theoretically, that semantic coding in long-term memory is also beneficial to performance in memory tasks"' (p. 699).
To evaluate this idea in the present experiments, we examined serial order recall performance under quiet and suppression conditions for two classes of words that are assumed to vary with respect to their semantic attributes: content and function words. Content words (mainly consisting of nouns, verbs, adjectives, and some adverbs) have strong semantic attributes. Function words (mainly consisting of prepositions, conjunctions, pronouns, articles, auxiliary verbs, and also some adverbs) do not have much semantic content, but rather have a syntactic function.

Because we manipulated a semantic rather than a lexical factor, Experiment 1 allowed us to ask whether there is a semantic contribution to span performance. If semantic information affects span performance independently of any contributions from the articulatory loop, then the effects of word class and suppression on performance should be statistically additive.

\section{EXPERIMENT 1}

\section{Method}

Subjects. Sixteen subjects were recruited from the subject pool at Wilfred Laurier University.

Stimuli. The stimuli consisted of 12 content words and 12 function words, matched on the basis of word frequency (Kucera \& Francis, 1967), number of letters, and number of syllables (content words: sit, farm, like, anxiety, great, healthy, second, big, sweet, place, typical, state; function words: nor, else, such, whereas, while, thereby, rather, yet, ought, those, despite, could).

Design. A $2 \times 2$ within-subjects factorial design was employed, with factors of viewing condition (quiet vs. suppression) and word type (content vs. function). The presentation of the four conditions was blocked, and order of presentation was determined by an incomplete Latin-square design.

The experiment consisted of 32 trials, 8 trials in each of the four blocked conditions. Each trial consisted of six items chosen without replacement from the stimulus pool. The order of presentation of function words within a list was randomized; the serial position in the corresponding content-word list was yoked (e.g., if the function word nor was in Serial Position 4 of the second list in the quiet condition, then its matched content word sit was also in Serial Position 4 of the second list in the quiet condition, content-word block).

Procedure. The words were presented in lowercase on a CRT slaved to an Apple IIe microcomputer. The items were presented in the middle of the screen at a rate of one item per second.

The subjects in the quiet condition were told that they would be presented with a list of words, and after reading each list they were to write the words down (from left to right) in the order in which they were presented. If they could not recall an item, they were to leave the space blank and continue with the recall of the other items.

The subjects in the suppression condition received identical instructions with the additional requirement that, while they viewed the words, they were to count out loud from 1 to 10 , repeatedly, at a rate of three items per second. The subjects started counting before the first word was presented, and stopped counting when the last word disappeared from the screen.

\section{Results and Discussion}

The total number of items recalled in their correct serial positions was calculated for each condition and converted to percentages. These values can be seen in Table 1 .

A two-way analysis of variance (ANOVA) yielded main effects of viewing condition, with the quiet condition showing better recall than the suppression condition $\left[F(1,15)=39.00, M S_{\mathrm{e}}=2,340, p<.001\right]$, and word 
Table 1

Percent Recall as a Function of Word Type in Experiment 1

\begin{tabular}{cccc}
\hline Viewing & \multicolumn{2}{c}{ Word Type } & \\
\cline { 2 - 3 } Condition & Content & Function & Difference \\
\hline Quiet & 67.3 & 59.4 & 7.9 \\
Suppression & 41.7 & 34.6 & 7.1 \\
\hline
\end{tabular}

type, with content words recalled better than function words $\left[F(1,15)=13.56, M S_{\mathrm{e}}=206, p<.01\right]$. The interaction between viewing condition and word type was not significant $(F<1)$.

The results of Experiment 1 replicate the standard finding that suppression severely impairs serial order recall (e.g., Baddeley et al., 1975). Experiment 1 also provides evidence that content words are better recalled than function words. Further, the magnitude of the word-type effect did not vary as a function of viewing condition. This suggests that semantic information plays a role in span performance that is independent of any contribution from the articulatory loop.

Although it is tempting to suppose that the superior recall of content words is solely due to its higher level of "semanticity" relative to function words, the results of several investigations caution us against drawing hasty conclusions when word-class effects are observed. An experiment conducted by Allport and Funnell (1981) provides a case in point. To test the widespread belief (see Coltheart, Patterson, \& Marshall, 1980) that reading performance for nouns is superior to that for verbs in the acquired reading disorder known as deep dyslexia, Allport and Funnell had 5 patients with this disorder read out loud 30 nouns and 30 verbs that were matched for imageability (the ease with which a word gives rise to a sensory impression of its referent). No difference between these two word classes was observed.

Davelaar and Besner (1988) provided evidence that imageability is also a critical issue with respect to investigations of the content-functor distinction. They analyzed work by Ehri (1977), who found that content words showed greater interference in the Stroop (1935) colornaming task than did function words. Davelaar and Besner replicated Ehri's finding, but showed in a subsequent experiment that the word-class effect disappeared when content and function words were matched for imageability.

The results from Allport and Funnell (1981) and Davelaar and Besner (1988) thus raise the possibility that the word-class effect observed in the present Experiment 1 may have been due to differences in imageability. Therefore, we addressed this issue in Experiment 2 by repeating Experiment 1 , but controlled for differences between content and function words along the imageability dimension. ${ }^{3}$

\section{EXPERIMENT 2}

\section{Method}

Subjects. A new sample of 16 undergraduates was recruited from the subject pool at Wilfred Laurier University.

Stimuli. The stimuli consisted of 20 content words and 20 function words, matched on the basis of word frequency, number of letters, num- ber of syllables, and imageability value (Friendly, Franklin, Hoffman, \& Rubin, 1982). The mean imageability ratings for the content and function words were 2.76 and 2.58 , respectively (content words: major, section, going, value, public, reason, become, suppose, balance, control, center, account, better, moment, coming, effect, basis, provide, aspect, began; function words: above, himself, after, always, around, really, indeed, perhaps, beneath, without, behind, herself, until, either, beyond, cannot, maybe, because, neither, among).

Design and Procedure. Each trial consisted of five items, chosen without replacement from the stimulus pool. The design and procedure were otherwise identical to that of Experiment 1.

\section{Results and Discussion}

Table 2 presents the percentage of items recalled in their correct serial positions for each of the four conditions.

A two-way ANOVA yielded a main effect of viewing condition, with the quiet condition showing better recall than the suppression condition $\left[F(1,15)=89.94, M S_{\mathrm{e}}=\right.$ $3,495, p<.001]$. Neither the main effect of word type nor the viewing condition $\times$ word type interaction were reliable (both $F_{\mathrm{S}}<1$ ).

Experiment 2, again, provides evidence that suppression drastically impairs serial order recall. However, there was no evidence that the content words were better recalled than the function words under either the quiet or suppression condition when these word classes were matched for imageability.

\section{GENERAL DISCUSSION}

The results of these two experiments are straightforward. Experiment 1 yielded a content-word advantage under both the quiet and suppression conditions. Experiment 2 showed that this putative word-class effect was eliminated when the words were matched for imageability. Although we are open to the view that some cognitive tasks tap the semantic/syntactic dimension presumed to be elemental to the content-functor distinction, there is no evidence that this distinction is reflected in memory performance as measured here.

However, the data can be taken to suggest that another semantic factor, imageability, plays a role in serial order recall. Inspection of the items used in Experiment 1 reveals that the content words (e.g., sit, farm, healthy) are more imageable than the function words (e.g., nor, else, thereby). More importantly, as indexed by the additive effects of word class and suppression found in the experiment, this imageability dimension appears to contribute to recall performance independently of the well-documented effects due to the articulatory loop (e.g., Baddeley et al., 1975; Besner \& Davelaar, 1982; Hulme et al., 1991).

The analysis of imageability in short-term-memory performance is, of course, by no means new. For example, Paivio and Smythe (1971) investigated short-term memory as a function of imageability by using the distractor technique introduced by Brown (1958) and Peterson and Peterson (1959). Paivio and Smythe found that recall for highimageability words was much better than that for low-imageability words. Further, Wickens (1972) has reviewed a number of other semantic variables that are strong determinants of short-term-memory performance vis-à-vis the Brown-Peterson paradigm. It would be interesting to know how much of a correlation there is between semantic dimensions that contribute to span performance of the type measured here, and those

Table 2

Percent Recall as a Function of Word Type in Experiment 2

\begin{tabular}{lccc}
\hline \multirow{2}{*}{$\begin{array}{l}\text { Viewing } \\
\text { Condition }\end{array}$} & \multicolumn{2}{c}{ Word Type } & \\
\cline { 2 - 3 } & Content & Function & Difference \\
\hline Quiet & 74.7 & 72.2 & 2.5 \\
Suppression & 35.3 & 37.7 & -2.4 \\
\hline
\end{tabular}


associated with the Brown-Peterson paradigm. To the extent that this correlation is small, it implies that the processes underlying short-termmemory and span performance, as investigated here, are somewhat distinct.

Another issue concerns whether lexicality, independently of semantics, influences serial order recall performance of subspan lists. One approach is to examine short-term-memory performance in patients who have no access to semantics from print, but exhjbit preserved "lexical knowledge" when they read out loud. The patient reported in Bub, Cancelliere, and Kertesz's (1985) investigation may be one such candidate.

Also of interest is the issue of whether there is a purely lexical contribution to serial order recall in such patients, given the recent debate concerning the existence of one or more "lexicons." With the advent of parallel distributed processing models, some theorists claim that there are no lexicons (e.g., Seidenberg \& McClelland, 1989, 1990); others dispute this claim (e.g., Besner, Twilley, McCann, \& Seergobin, 1990; Coltheart, Curtis, Atkins, \& Haller, 1993). The "no lexicon" view would seem to predict that, provided that words and nonwords are matched for orthographic and phonological characteristics, there ought to be no lexical effects in the serial order recall of a patient with no access to semantics.

In conclusion, as in other domains (e.g., word and object recognition), performance in the present task is subserved by a multicomponent system. Semantic aspects of long-term memory is one of those components.

\section{REFERENCES}

Allport, D. A., \& FunNell, E. (1981). Components of the mental lexicon. Philosophical Transactions of the Royal Society of London: Series B, 295, 397-410.

BADDELEY, A. D. (1986). Working memory. London: Oxford University Press.

BADDELEY, A. D., \& Hitch, G. (1974). Working memory. In G. H. Bower (Ed.), The psychology of learning and motivation (Vol. 8, pp. 47-90). New York: Academic Press.

Baddeley, A. D., Thomson, N., \& Buchanan, M. (1975). Word length and the structure of short-term memory. Journal of Verbal Learning \& Verbal Behavior, 14, 575-589.

BesNer, D. \& DavelaAR, E. (1982). Basic processes in reading: Two phonological codes. Canadian Journal of Psychology, 36, 701-711.

Besner, D., TWILLEy, L., MCCANN, R. S., \& SEergobin, K. (1990). On the association between connectionism and data: Are a few words necessary? Psychological Review, 97, 432-446.

Brooks, J. O., \& WATKINS, M. J. (1990). Further evidence of the intricacy of memory span. Journal of Experimental Psychology: Learning, Memory, \& Cognition, 16, 1134-1141

Brown, J. (1958). Some tests of the decay theory of immediate memory. Quarterly Journal of Experimental Psychology, 10, 12-21.

Bub, D., Cancelliere, A., \& Kertesz, A. (1985). Whole-word and analytic translation of spelling to sound in a non-semantic reader. In K. E. Patterson, J. C. Marshall, \& M. Coltheart (Eds.), Surface dyslexia (pp. 15-34). Hillsdale, NJ: Erlbaum.

Caplan, D., Rochon, E., \& Waters, G. S. (1992). Articulatory and phonological determinants of word length effects in span tasks. Quarterly Journal of Experimental Psychology, 45A, 177-192.

Coltheart, M., Curtis, B., Atkins, P., \& Haller, M. (1993). Models of reading aloud: Dual-route and parallel-distributed-processing approaches. Psychological Review, 100, 589-608.

Coltheart, M., Patterson, K. E., \& Marshall, J. C. (1980). Deep dyslexia. London: Routledge \& Kegan Paul

DAvelAAR, E., \& BESNER, D. (1988). Word identification: Imageability, semantics, and the content-functor distinction. Quarterly Journal of Experimental Psychology, 40A, 788-799.

EHRI, L. C. (1977). Do adjectives and functors interfere as much as nouns in naming pictures? Child Development, 48, 697-701.

Erucsson, K. A., Chase, W. G., \& Faloon, S. (1980). Acquisition of a memory skill. Science, 208, 1181-1182.

Friendiy, M. L., Frankin, P., Hofrman, D., Rubin, D. C. (1982) The Toronto word pool: Norms for imagery, concreteness, orthographic varjables, and grammatical usage for 1080 words. Behavior Research Methods \& Instrumentation, 14, 375-399.
Hulme, C., Maughan, S., \& Brown, G. D. A. (1991). Memory for familiar and unfamiliar words: Evidence for a long-term memory contribution to short-term memory span. Journal of Memory \& Language, 30, 685-701.

Hulme, C., \& TORDOFF, V. (1989). Working memory development: The effects of speech rate, word length, and acoustic similarity on serial recall. Journal of Experimental Child Psychology, 47, 72-87.

KaUSLER, D. H. , PUCKETt, J. M. (1979). Effects of word frequency on adult age differences in word memory span. Experimental Aging Research, 5, 161-169.

KuCERA, H., Francis, W. N. (1967). Computational analysis of present-day American English. Providence, RI: Brown University Press.

MiLler, G. A. (1956). The magical number seven, plus or minus two: Some limits to our capacity for processing information. Psychological Review, 63, 81-97.

MorTon, J. (1969). Interaction of information in word recognition. Psychological Review, 76, 165-178.

MURRAY, D. (1968). Articulation and acoustic confusability in shortterm memory. Journal of Experimental Psychology, 78, 679-684.

Paivio, A., \& SMYthe, P. C. (1971). Word imagery, frequency, and meaningfulness in short-term memory. Psychonomic Science, 22, 333-335.

Peterson, L. R., Peterson, M. J. (1959). Shott-term retention of individual verbal items. Journal of Experimental Psychology, 58, 193-198.

SeidenberG, M. S., \& McClelland, J. L. (1989). A distributed, developmental model of word recognition and naming. Psychological Review, 96, 523-568.

SeidenberG, M. S., \& MCClelland, J. L. (1990). More words but still no lexicon: A reply to Besner et al. (1990). Psychological Review, 97, 447-452.

STASZEWSKI, J. J. (1988). Skilled memory and expert mental calculation. In M. T. H. Chi, R. Glaser, \& M. J. Farr (Eds.), The nature of expertise. Hillsdale, NJ: Erlbaum.

STROoP, J. R. (1935). Studies of the interference in serial verbal reactions. Joumal of Experimental Psychology, 18, 643-662.

Tehan, G. , Humphreys, M. S. (1988). Articulatory loop explanations of memory span and pronunciation rate correspondences: $\mathrm{A}$ cautionary note. Bulletin of the Psychonomic Sociery, 26, 293-296.

Warxins, M. I. (1977). The intricacy of memory span. Memory \& Cognition, 5, 529-534

WiCKENS, D. D. (1972). Characteristics of word encoding. In A. W. Melton \& E. Martin (Eds.), Coding processes in human memory (pp. 191-215). Washington, DC: Winston.

\section{NOTES}

1. Watkins (1977) has reported a word frequency effect in span, also suggesting a lexical/semantic influence. We note, however, that (1) it has proven difficult to replicate (e.g., Kausler \& Puckett, 1979) and (2) it is unclear whether it should be classified as a lexical or semantic effect.

2. Brooks and Watkins (1990) report a semantic influence on span performance. However, they note that "it is possible that words can be read faster [italics added] when they are semantically related to their [list] neighbours than when they are semantically unreiated to their [ist] neighbours. Indeed, we have tested and confirmed this possibility in a subsidiary experiment"' (p. 1139). Thus, although their experiment demonstrates a semantic/long-term-memory influence on span performance, it does not demonstrate a semantic influence that is independent of effects attributable to the articulatory loop.

3. We note that Tehan and Humphreys (1988) have reported results identical to those in Experiment 1. However, they too failed to match content and function words for imageability.

(Manuscript received May 19, 1993 revision accepted for publication August 16, 1993.) 